\title{
Enhanced at puberty 1 (EAP1) is a new transcriptional regulator of the female neuroendocrine reproductive axis
}

\author{
Sabine Heger, ${ }^{1}$ Claudio Mastronardi, ${ }^{2}$ Gregory A. Dissen, ${ }^{2}$ Alejandro Lomniczi, ${ }^{2}$ Ricardo Cabrera, ${ }^{2}$ \\ Christian L. Roth, ${ }^{2}$ Heike Jung, ${ }^{2}$ Francesco Galimi, ${ }^{3,4}$ Wolfgang Sippell, ${ }^{5}$ and Sergio R. Ojeda ${ }^{2}$ \\ ${ }^{1}$ Hospital for Children and Adolescents, University of Leipzig, Leipzig, Germany. ${ }^{2}$ Division of Neuroscience, Oregon National Primate Research Center, \\ Oregon Health \& Science University, Beaverton, Oregon, USA. ${ }^{3}$ Department of Biomedical Sciences/Istituto Nazionale di Biostrutture e Biosistemi, \\ University of Sassari Medical School, Sassari, Italy. ${ }^{4}$ Salk Institute for Biological Studies, La Jolla, California, USA. \\ ${ }^{5}$ Division of Pediatric Endrocrinology, Department of Pediatrics, University Schleswig-Holstein, Campus Kiel, Kiel, Germany.
}

\begin{abstract}
The initiation of mammalian puberty and the maintenance of female reproductive cycles are events controlled by hypothalamic neurons that secrete the decapeptide gonadotropin-releasing hormone (GnRH). GnRH secretion is, in turn, controlled by changes in neuronal and glial inputs to GnRH-producing neurons. The hierarchical control of the process is unknown, but it requires coordinated regulation of these cell-cell interactions. Here we report the functional characterization of a gene (termed enhanced at puberty 1 [EAP1]) that appears to act as an upstream transcriptional regulator of neuronal networks controlling female reproductive function. EAP1 expression increased selectively at puberty in both the nonhuman primate and rodent hypothalamus. EAP1 encoded a nuclear protein expressed in neurons involved in the inhibitory and facilitatory control of reproduction. EAP1 transactivated genes required for reproductive function, such as GNRH1, and repressed inhibitory genes, such as preproenkephalin. It contained a RING finger domain of the $\mathrm{C} 3 \mathrm{HC} 4$ subclass required for this dual transcriptional activity. Inhibition of EAP1 expression, targeted to the rodent hypothalamus via lentivirusmediated delivery of EAP1 siRNAs, delayed puberty, disrupted estrous cyclicity, and resulted in ovarian abnormalities. These results suggest that EAP1 is a transcriptional regulator that, acting within the neuroendocrine brain, contributes to controlling female reproductive function.
\end{abstract}

\section{Introduction}

Much has been learned in recent years about the neuroendocrine mechanisms controlling both the onset of mammalian puberty and the maintenance of female reproductive cyclicity. Both events require changes in the release of gonadotropin-releasing hormone $(\mathrm{GnRH})$ from neurosecretory neurons, mostly located in the medial basal hypothalamus $(\mathrm{MBH})$ of primates and the preoptic region of rodents $(1,2)$. These changes are, in turn, determined by modifications in transsynaptic $(3,4)$ and glial $(5)$ inputs to the GnRH neuronal network. Studies in developing monkeys and rodents have shown that while the transsynaptic changes involve a coordinated increase in excitatory inputs and a reduction in inhibitory influences $(1,4,6)$, the glial component of the system is predominantly facilitatory and exerted by growth factors that directly or indirectly stimulate $\mathrm{GnRH}$ secretion $(2,5)$.

The general composition of each of these regulatory systems is also known. Thus, the excitatory transsynaptic regulation of GnRH secretion is provided by glutamatergic neurons and the newly discovered kisspeptin-producing neurons $(2,7)$; the inhibitory counterpart of this circuitry depends principally on GABAergic neurons but also on opiatergic neurons that employ different peptides and

Nonstandard abbreviations used: ARC, arcuate nucleus; AVPV, anteroventral periventricular nucleus; CTX, cerebral cortex; EAP1, enhanced at puberty 1; eGFP, enhanced GFP; FSH, follicle-stimulating hormone; GnRH, gonadotropin-releasing hormone; $\mathrm{LH}$, luteinizing hormone; $\mathrm{MBH}$, medial basal hypothalamus; POA, preoptic area; shRNA, short hairpin RNA; TTF1, thyroid transcription factor 1; TU, transducing unit(s).

Conflict of interest: The authors have declared that no conflict of interest exists. Citation for this article: J. Clin. Invest. 117:2145-2154 (2007). doi:10.1172/JCI31752. a variety of different receptors for inhibitory neurotransmission (reviewed in ref. 6). Adding complexity to this regulatory system is the fact that GABA not only inhibits GnRH secretion by acting on neuronal subsets connected to the GnRH neuronal network $(2,6)$ but can also excite GnRH neurons directly (8).

What are the genes that, acting within the diverse neuronal and/or glial components of this regulatory network, coordinate - at the molecular level - first the activational process that leads to the onset of puberty and then those events underlying female reproductive cyclicity? Although it would appear intuitively clear that this coordination requires the participation of a host of functionally interacting genes $(9,10)$, the importance of such a polygenic configuration for the initiation of reproductive capacity has only recently been fully appreciated $(10,11)$, perhaps due to the earlier perception that human central precocious puberty is not genetically determined but instead is sporadic in nature - an assumption now disproved (12). Accepting the idea of such a gene network also requires considering the existence of a level of control provided by upstream transcriptional regulators acting within functionally linked neuronal and glial subsets (13). In other systems, these genes - which reside at the core of regulatory networks $(14,15)$ - have been shown to both maintain the hierarchical structure of the network and provide the system with redundancy and combinatorial diversity (15). Transcription factors involved in the central control of reproductive function would be expected to establish the conditions required for the productive engagement of neuron-to-neuron, neuron-to-glia, and glia-to-neuron circuitries controlling GnRH secretion, regardless of the transcriptional process they control. 
A

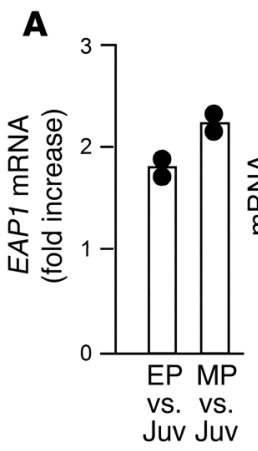

B

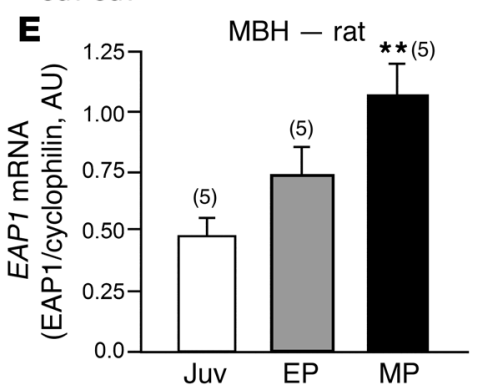

$\mathrm{MBH}-$ monkey C CTX - monkey

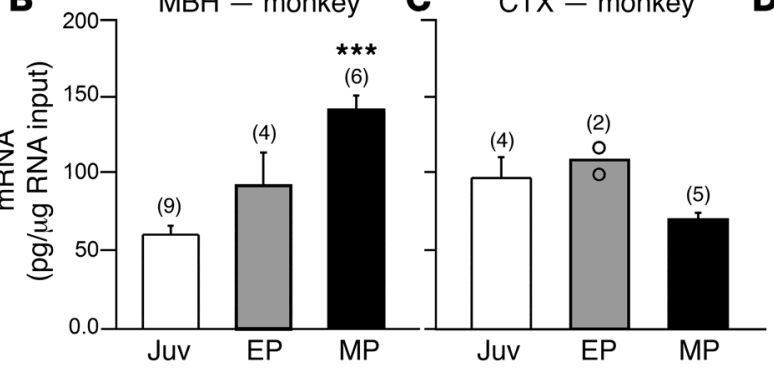

$\mathbf{F}$

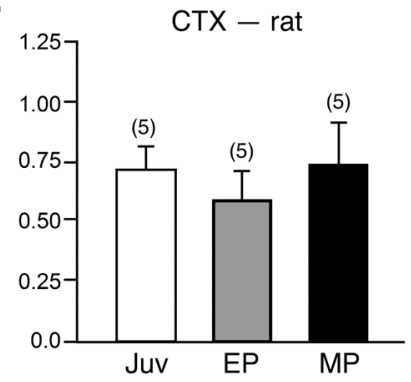

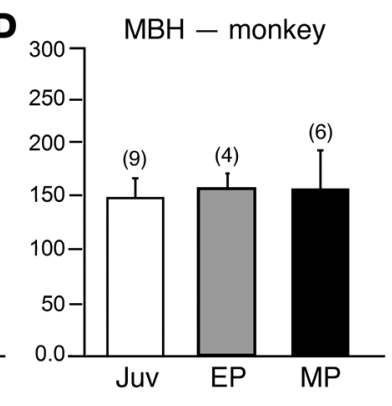

criteria described in Methods. Among the genes whose expression increased in the $\mathrm{MBH}$, but not in the CTX, at early puberty and further at midpuberty, we identified a gene (Figure 1A) provisionally named C14ORF4 (16). C14ORF4 is an intronless gene that maps to human chromosome $14, \mathrm{q} 24.3$ (16), a region located within a known "hotspot" for human sexual precocity $(17,18)$. Using real-time PCR (Supplemental Note 2), we confirmed the pubertal increase in hypothalamic C14ORF4 expression detected by the arrays (Figure 1B) and determined that such an increase does not occur in the CTX, a brain region unrelated to the neuroendocrine control of puberty (Figure 1C). C14ORF4 mRNA content in the CTX was already at mature levels in juve-

To identify candidate genes that may fulfill this role, we performed a global analysis of gene expression in the developing female monkey hypothalamus and found C14ORF4, a predicted gene of unknown function (16), to be one of the genes whose expression increases consistently at the time of puberty. We selected C14ORF4 for further study because of earlier findings showing that abnormalities in the region where C14ORF4 is located in chromosome $14(14 q 23-14 q 32)$ are invariably associated with precocious puberty in humans $(17,18)$. C14ORF4 is located in $14 \mathrm{q} 24.3$. Our results show that C14ORF4, now renamed EAP1 (see below) is a transcriptional factor that, acting within neuronal networks of the neuroendocrine brain, is required for the timely initiation of female puberty and maintenance of female reproductive cyclicity.

\section{Results}

To identify genes that may be involved in the transcriptional control of primate puberty, we employed DNA microarrays (Supplemental Note 1; supplemental material available online with this article; doi:10.1172/JCI31752DS1) and RNA from the $\mathrm{MBH}$ and cerebral cortex (CTX) of female rhesus monkeys at 3 different developmental stages: juvenile ( 9 months to 1.8 years of age), early pubertal (2-2.9 years of age), and mid-pubertal (3.1-4 years of age). The animals were classified in each of these stages using nile animals, suggesting that developmental changes in C14ORF4 expression in this brain region are complete long before puberty, independent of the stage of sexual maturation.

Human C14ORF4 encodes a predicted protein that shares approximately $40 \%$ homology with the hypothetical protein CAB45750. No changes in CAB45750 expression occurred in the monkey hypothalamus (Figure 1D), indicating that, in addition to its regional specificity, the increase in C14ORF4 mRNA abundance is also gene specific. Expression of C14ORF1 (NM_007176), another predicted gene mapping to chromosome $14 \mathrm{q} 24$, did not change at puberty, as assessed by both DNA arrays and real-time PCR (data not shown). Like female monkeys, female rats undergoing puberty exhibited an increase in hypothalamic, but not CTX, C14ORF4 mRNA abundance (Figure 1, E and F, respectively). This increase was initiated during early puberty (30-35 days of age) and, as in monkeys, became distinctly evident at mid-puberty (32-37 days of age). Early puberty corresponds to the previously described early proestrous phase of puberty, a developmental stage during which the first manifestations of enhanced estrogen secretion become apparent in female rats (2). Mid-puberty corresponds to the late proestrous phase, which is the day of the first preovulatory surge of gonadotropins. Although puberty in the rat is a very compressed process, we consider this stage to be mid-puberty, because completion of the pubertal changes evidenced by the first ovula- 


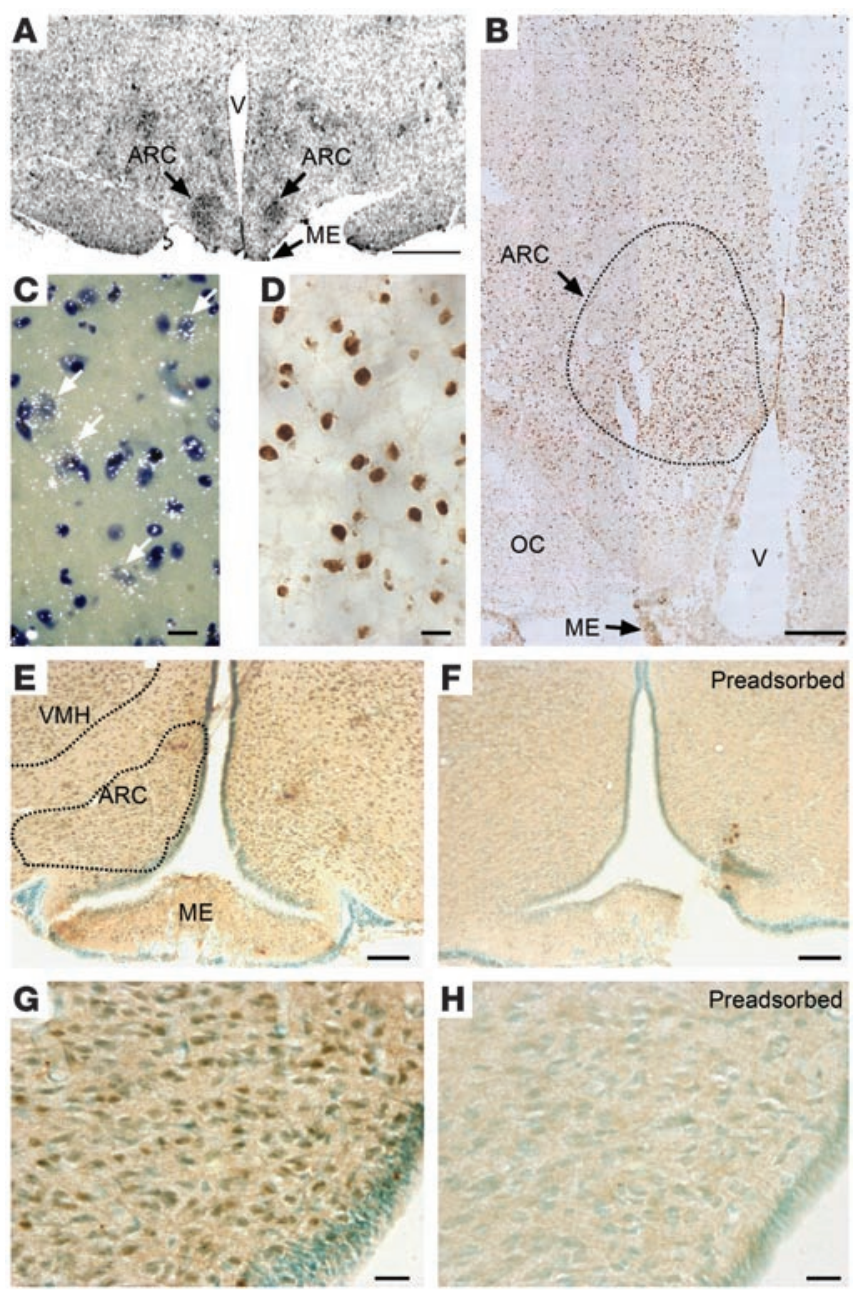

tion does not occurs until the next day (see Methods for inclusion criteria). Based on the above-described findings, we renamed the gene enhanced at puberty 1 (EAP1).

In the primate hypothalamus, EAP1 mRNA detected by in situ hybridization (Supplemental Note 3) was abundant in cells of hypothalamic nuclei involved in the control of GnRH secretion, such as the arcuate nucleus (ARC) (Figure 2, A and C). Consistent with the presence of a nuclear localization signal in the EAP1 sequence (16), EAP1 protein detected by immunohistochemistry using polyclonal antibodies (Supplemental Note 3) was localized to cell nuclei (Figure 2, B and D). Using the same antibodies, we found that EAP1 protein is also expressed in regions of the female rat hypothalamus involved in reproductive control, such as the medial preoptic area (POA), ARC, and ventromedial nucleus (VMH). These findings are illustrated in Figure 2E, which shows at low magnification the presence of immunoreactive EAP1 in cell nuclei of the ARC and VMH of a 28-day-old juvenile female rat. Preadsorption of the antibodies with the antigenic peptide completely eliminated the staining (Figure 2F). Higher-magnification views of both conditions are shown in Figure 2, G and H, respectively.

In brain sections from 28-day-old juvenile female rats, EAP1 protein was detected in the nuclei of neurons involved in both the facilitatory and inhibitory control of GnRH secretion. For example, EAP1 was present in GnRH neurons, which are required for the

\section{Figure 2}

The EAP1 gene is expressed in subregions of the nonhuman primate and rat hypothalamus involved in reproductive control. (A) Low-magnification image showing that EAP1 mRNA expression is prominent in cells of the ARC of the primate hypothalamus as assessed by in situ hybridization using a monkey-specific [ ${ }^{35}$ S]UTP-labeled EAP1 cRNA probe. The section shown is from an 8-year-old adult female monkey. $\mathrm{ME}$, median eminence of the hypothalamus; OC, optic chiasm; $\mathrm{V}$, third ventricle. Scale bar: $300 \mu \mathrm{m}$. (B) Montage image of the monkey hypothalamus (adult, 8-year-old female monkey) showing that EAP1 immunoreactive protein is preferentially localized to cells of the ARC. The dotted line outlines the medial and lateral ARC. Scale bar: $200 \mu \mathrm{m}$. (C) High-magnification view of $\mathbf{A}$ showing that EAP1 mRNA is localized to cell nuclei that appear to be neuronal because they are lightly stained with thionin (examples denoted by arrows). Scale bar: $20 \mu \mathrm{m}$. (D) High-magnification view of the ARC showing immunoreactive EAP1 in neuronal nuclei. Scale bar: $20 \mu \mathrm{m}$. (E) Low-magnification view of the $\mathrm{MBH}$ from a 28-day-old prepubertal female rat showing EAP1 staining in cell nuclei of the ARC and ventromedial $(\mathrm{VMH})$ nuclei (outlined by dotted lines). The immunohistochemical reaction was developed to a brown color with diaminobenzidine hydrochloride (Supplemental Note 3 ), and the cell nuclei were counterstained with $0.1 \%$ methyl green. (F) Lack of EAP1 staining in an adjacent section incubated with EAP1 antibodies preadsorbed with the antigenic peptide used to prepare the antibodies (10 $\mu$ g peptide/ml antiserum, overnight at $\left.4^{\circ} \mathrm{C}\right)$. (G) Highermagnification view of the ARC showing EAP1 staining (brown) in cell nuclei. Some cells did not contain EAP1, so their nuclei have only a green color. (H) Adjacent section stained with peptide-preadsorbed EAP1 antibodies. Scale bars: $100 \mu \mathrm{m}$ (in $\mathbf{E}$ and $\mathbf{F}$ ); $20 \mu \mathrm{m}$ (G and $\mathbf{H}$ ).

initiation of puberty and adult reproductive function (Figure 3, $\mathrm{A}$ and $\mathrm{B}$ ), and preproenkephalinergic neurons (Figure 3, D-F), which are involved in the inhibitory control of $\mathrm{GnRH}$ secretion $(19,20)$. Using confocal microscopy followed by constrained iterative deconvolution and 3D reconstruction, we observed (Figure 3C) that EAP1 (red) was present in nuclear regions lacking condensed chromatin (blue). Since these regions are thought to be transcriptionally active (21), such a localization suggests that EAP1 may be involved in gene regulation. EAP1 also contains a coiled-coil domain (16), indicative of participation in protein-protein interaction (22), and a C3HC4 RING finger domain sequence (23), implicating EAP1 in ubiquitination (24). Because of their opposite roles in the control of reproductive function, we selected the GnRH and the preproenkephalin genes to experimentally test the ability of EAP1 to regulate gene transcription. Using functional promoter assays (Supplemental Note 4), we determined that EAP1 transactivates the $\mathrm{GnRH}$ promoter (Figure $3 \mathrm{G}$ ) but represses the preproenkephalin promoter (Figure 3, H and I). This latter effect was observed in both GnRH-producing GT1-7 cells (Figure 3H) and HiB5 neuronal hippocampal cells (Figure 3I), indicating that the dual transcriptional activity of EAP1 is promoter specific. It also requires an intact RING finger domain; deletion of this domain, or a single amino acid substitution (the first cysteine to alanine) earlier shown to abolish the biological activity of the RING finger domain (25), obliterated both the repressive (preproenkephalin) and the transactivating ( $\mathrm{GnRH}$ ) effects of EAP1 (Figure 3, G-I). Although basal activity of the GnRH promoter was noticeable lower than that of the preproenkephalin promoter, it is unlikely that this reduced activity may have influenced the response of the GnRH promoter to EAP1. We observed a stimulatory effect of EAP1 on this promoter in several assays, regardless of the basal level of activity. For instance, in an assay in which the basal activity 
A

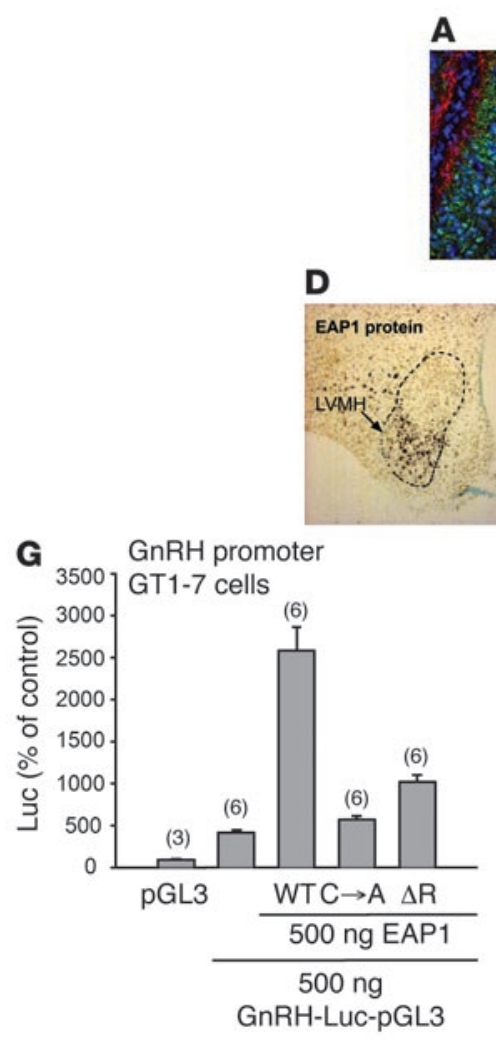

B

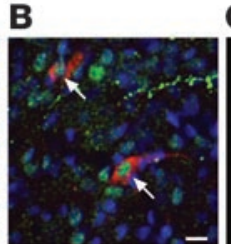

E

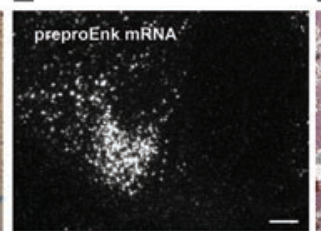

H preproEnk promoter

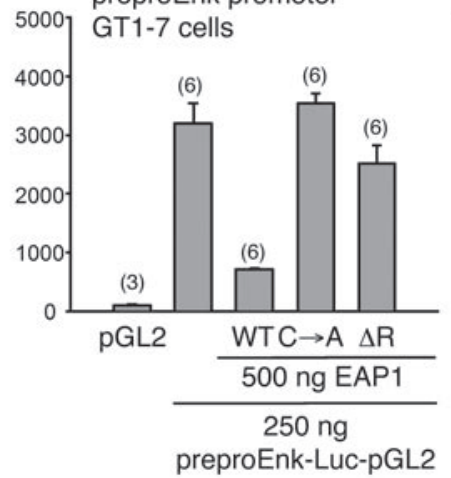

c

$\mathbf{F}$
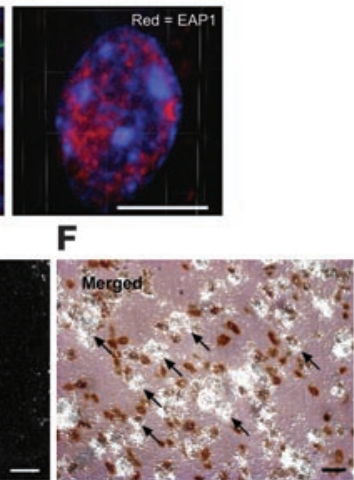

I ${ }_{10000}^{12000}$. HiB5 cells

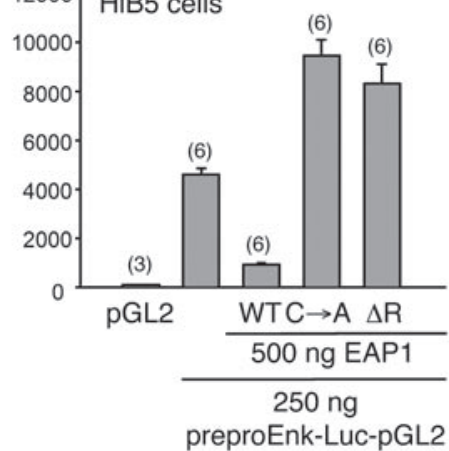

\section{Figure 3}

EAP1 is a nuclear protein with dual transcriptional activity expressed in hypothalamic neurons that facilitate or inhibit the initiation of female puberty. (A) Confocal image of a subregion of the rat POA from a 28-day-old female rat showing that EAP1 has a predominant nuclear localization (green). Notice that not all neurons contain EAP1, as evidenced by the lack of green staining in cell nuclei identified by Hoechst staining (blue). Long arrows indicate EAP1-positive cells; short arrows indicate cells lacking EAP1. (B) Detection of EAP1 (green) in the nucleus of GnRH neurons (red, arrows). (C) Wide-field image of a neuron labeled for EAP1 and Hoechst after constrained iterative deconvolution and 3D reconstruction showing that EAP1 (red) is not associated with condensed chromatin (blue). Scale bars: $40 \mu \mathrm{m}$ (A); $20 \mu \mathrm{m}$ (B); $5 \mu \mathrm{m}$ (C). (D-F) Combined immunohistochemistry-in situ hybridization of brain sections from 28- to 30-day-old female rats showing that EAP1 protein is abundant (D) in cells of the latero-ventral portion of the ventromedial nucleus (LVMH) of the hypothalamus, identified as enkephalinergic by their content of preproenkephalin (preproEnk) mRNA (E and $\mathbf{F}$ ). The higher-magnification image in $\mathbf{F}$ shows that all preproenkephalin mRNA-containing neurons (white grains) are EAP1 positive (brown staining; examples denoted by arrows). 3V, third ventricle. (G-I) EAP1 has a dual transcriptional regulatory activity that requires an intact RING finger domain. (G) In GT1-7 GnRH-producing cells, EAP1 transactivates the GnRH promoter. $(\mathbf{H})$ In the same cells, it represses the preproenkephalin promoter. (I) This repressive activity is also seen in hippocampal neuroprogenitor HiB5 cells. Both the transactivating and repressive activities of EAP1 are abolished by either a single amino acid substitution $(C \rightarrow A)$ in the EAP1 RING finger domain or by deletion of this domain $(\Delta R)$. Numbers above bars represent number of wells/group, and error bars are SEM.

of the GnRH promoter was high $(1,279 \% \pm 61 \%$ over control pGL3 levels; $n=6)$, EAP1 at the same dose shown in Figure $3 \mathrm{G}$ increased these values to $3,647 \% \pm 220 \%(n=6)$.

To determine the functional importance of EAP1 in the in vivo control of female reproductive function, we used a loss-of-function approach. We first synthesized siRNAs (Supplemental Note 5) and found that 2 of them (siR1 and siR3) reduced EAP1 mRNA levels by greater than $80 \%$ in cell lines (Supplemental Figure 1A). To prove target specificity, we generated silent mutations in EAP1 mRNA region targeted by siR1 or siR3 (26) (Supplemental Note 6). These mutations rescued EAP1 mRNA from the inhibitory effect of the EAP1 siRNAs (Supplemental Figure 1B). We then used the siR1 or siR3 sequences to generate short hairpin RNAs (shRNAs) within a lentiviral context (Figure 4, A and B) as previously described (27). Using these viral particles (see Methods and Supplemental Figure 2), we infected neuronal HiB5 cells to assess the shRNA silencing potency. The most effective shRNA was EAP1 sh1, which decreased
EAP1 mRNA expression by approximately 90\% (Figure 4C). This effect was not associated with activation of the interferon pathway $(26,28)$, as assessed by the lack of changes in $2^{\prime}, 5^{\prime}$ oligoadenylate synthetase-1 mRNA, a major interferon target (26) (Figure 4, D and E; Supplemental Note 7).

After satisfying the dual criterion of potency and specificity, we determined the effect of a region-specific decrease in EAP1 production on the onset of female puberty and adult reproductive cyclicity. One microliter of EAP1 sh1-producing lentivirus $\left(3.6 \times 10^{6}\right.$ transducing units $[\mathrm{TU}] / \mu \mathrm{l})$ was microinjected bilaterally into the POA of juvenile 23-day-old female rats (Supplemental Note 8). In this species, the POA contains most of the GnRH neurons involved in the hypothalamic control of pituitary gonadotropin secretion and is required for the recurrent surges of gonadotropin release during the estrous cycle (29). Control animals were injected with enhanced GFP-producing (eGFP-producing) viruses carrying the U6 promoter cassette alone (LV eGFP). Identification of 

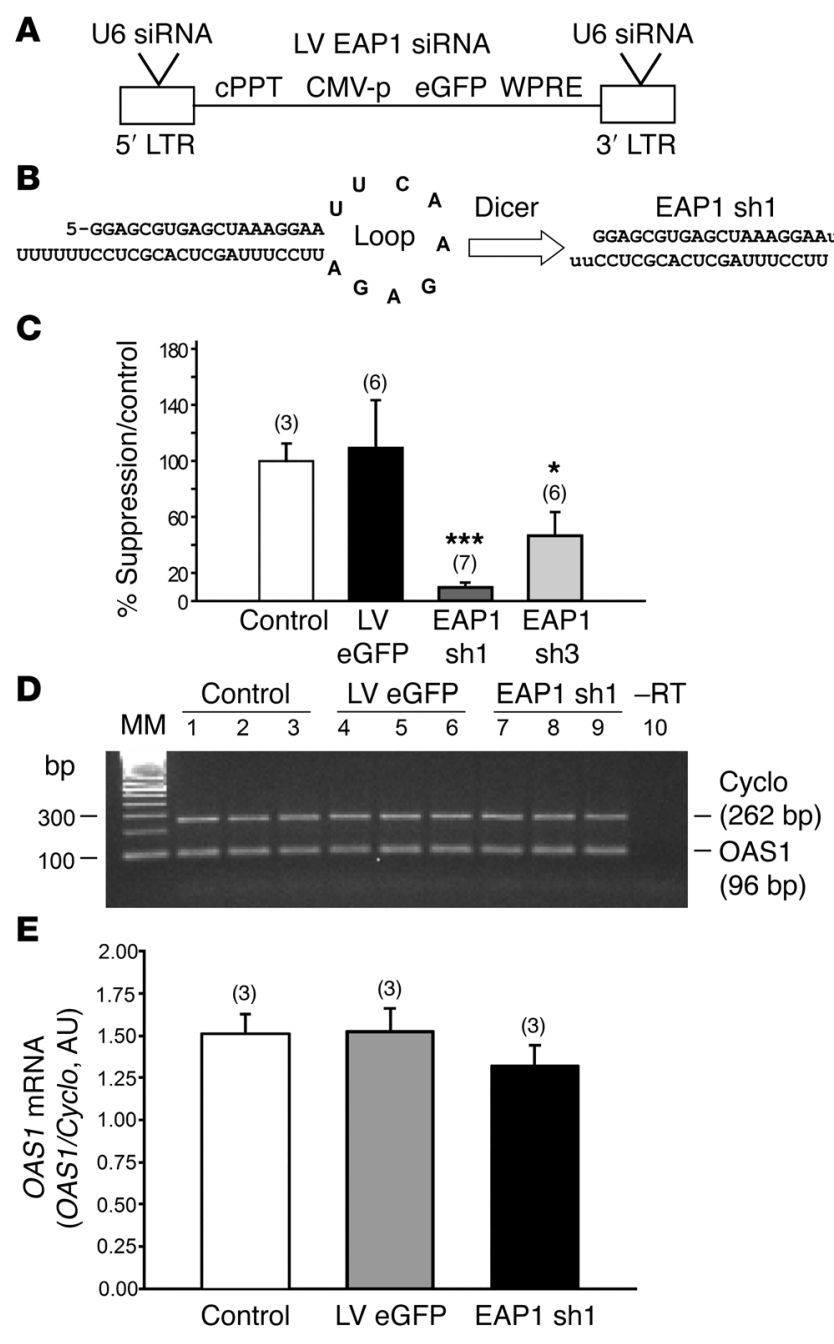

eGFP-expressing cells showed that the injection site was correctly targeted to the POA in 8 LV eGFP-injected controls and 6 EAP1 sh1-injected rats. Well-placed injections infected neurons located in the anteroventral periventricular nucleus (AVPV) and/or the lateral aspect of this nucleus (Figure 5, A and B). The AVPV is a region of the POA required for the preovulatory discharge of gonadotropins (30). Figure 5A shows eGFP-labeled cells located along the lateral borders of the AVPV; Figure 5B shows eGFP-positive cells in the dorsal and medial aspects of the right AVPV; although no positive cells were seen in the left AVPV, subsequent sections demonstrated the presence of infected cells in this region (data not shown). An example of misplaced injections (too lateral and too caudal to the POA) is shown in Figure 5C. A higher-magnification view revealed that most infected cells were neurons (Figure 5D), including GnRH neurons (Figure 5E). EAP1 sh1-treated cells (green) had a reduced content of EAP1 immunoreactive material compared with noninfected cells (red only) (Figure 5, F-H). Semiquantitative image analysis (Supplemental Note 9) showed that this decrease was significant $(P<0.01)$ (Figure 5I).

Assessment of sexual development and reproductive cyclicity demonstrated that the onset of puberty (defined by the time of first ovulation) was delayed in rats receiving EAP1 sh1 in the POA as compared with LV eGFP-injected rats (Figure 6A). EAP1-knock-

\section{Figure 4}

Lentivirus-mediated delivery of EAP1 siRNAs decreases EAP1 mRNA expression both in vitro and in vivo. (A) Diagram of the lentivirus construct (27) used, showing the site of insertion of a U6 promoter-driven shRNA-expressing cassette. (B) Generation of EAP1 sh1 from the U6 promoter-directed transcriptional cassette. (C) Inhibition of EAP1 gene expression in HiB5 hippocampal neural progenitor cells by EAP1 sh1 and -3 , measured 48 hours after infection. EAP1 mRNA content was detected by semiquantitative PCR. Bars are mean \pm SEM; $n=6-7$ wells/group, except in the case of noninfected control $(n=3)$. ${ }^{\star} P<0.05$; ${ }^{* \star} P<0.01$ versus control or LV-infected group. (D and E) Lack of changes in 2', $5^{\prime}$ oligoadenylate synthetase-1 (OAS1) mRNA abundance after in vitro infection of hypothalamic slices with lentiviral particles carrying EAP1 sh1. The slices were prepared and infected as described in Supplemental Note 7. OAS1 mRNA was measured by semiquantitative PCR 72 hours after infection. (D) PCR products sizefractionated in a $2 \%$ agarose gel stained with ethidium bromide. $-\mathrm{RT}$, no reverse transcription product. MM, molecular markers. (E) Densitometric analysis of the gel shown in D. Cyclophilin (Cyclo) mRNA, a housekeeping gene, was used as the normalizing unit. Accordingly, OAS1 mRNA levels are expressed as mean \pm SEM (AU) of the OAS1/ cyclophilin mRNA ratio calculated for each group $(n=3)$.

down rats also failed to cycle normally (Figure 6, B and C), exhibiting prolonged episodes in estrus (Figure 6D) and reduced plasma luteinizing hormone (LH), follicle-stimulating hormone (FSH), and estradiol levels (Figure 6, E-G). These hormonal deficits were accompanied by delayed growth of ovarian follicles, evidenced by an accumulation of antral follicles (Figure 7A). A more detailed analysis of the results revealed that this accumulation was due to an increased number of medium-size follicles $(200-400 \mu \mathrm{m})$ in EAP1 sh1-injected rats as compared with control animals (Figure 7B). Surprisingly, the ovaries from EAP1 sh1-injected rats also contained large follicular and luteal cysts (Figure 7, D and E), 2 abnormal structures that were absent in LV eGFP-injected rats (Figure 7C).

We next determined whether EAP1 expression is regulated by hormonal signals of peripheral origin involved in the control of reproductive function. In a series of experiments (data not shown), we found that neither hypothalamic EAP1 mRNA abundance nor the transcriptional activity of the EAP1 gene is increased by ovarian steroids. We then assessed EAP1 mRNA levels in the MBH of adult (80-day-old) ob/ob mice (Supplemental Note 2). These animals lack leptin, an adipocyte-derived hormone previously implicated in facilitating the initiation of puberty (31) and known to be a metabolic signal to the reproductive system (32). The results showed that EAP1 mRNA abundance is unperturbed in the absence of leptin (Supplemental Figure 3). Thus, the pubertal activation of hypothalamic EAP1 expression appears to result from centrally originated events.

\section{Discussion}

A substantial body of literature has made clear that no isolated pathway or cellular subset is solely responsible for the neuroendocrine control of puberty and the subsequent cyclic, repetitive activation of the hypothalamic-pituitary-ovarian axis. Instead, this control is likely exerted by regulatory gene networks hierarchically arranged. It would also appear that attainment of sexual maturity depends on the faithful execution of a genetically controlled developmental program requiring bidirectional cell-cell communication. Intrinsic to this concept is the long-suspected - but still unproven - existence of upstream genes controlling at the transcriptional 

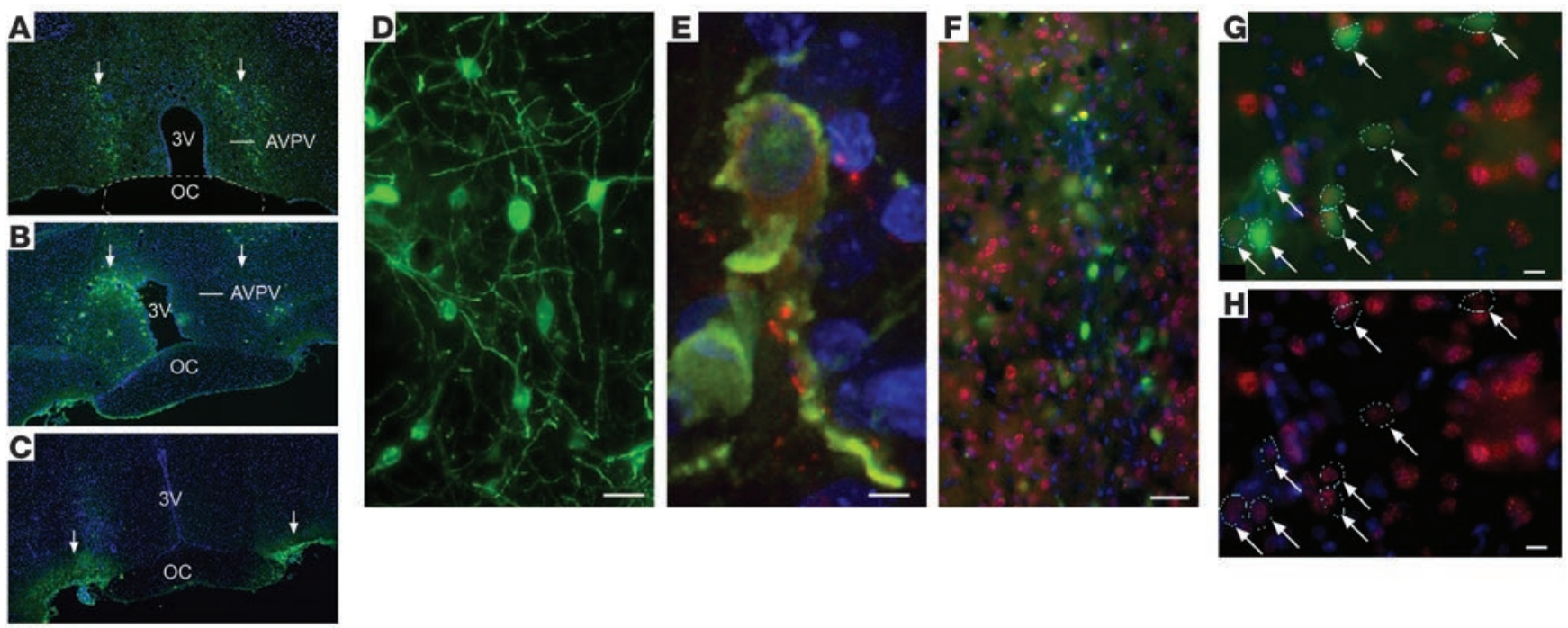

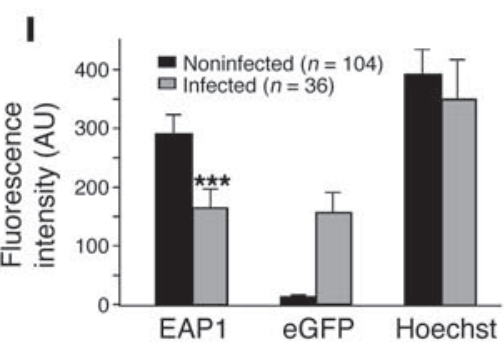

Figure 5

In vivo lentivirus-mediated delivery of EAP1 shRNAs to the rat POA decreases EAP1 protein levels. The images illustrate results derived from 8 control animals injected with LV eGFP, 6 animals correctly injected with EAP1 sh1, and 2 animals with misplaced injections of EAP1 sh1. (A and $\mathbf{B})$ Examples of well-placed injections carrying EAP1 sh1-encoding lentiviruses. The cells infected are seen along the lateral edge (A) or dorsal-medial aspect (B) of the AVPV. (C) Example of misplaced injections (too lateral and too caudal). (D) Higher-magnification image showing that most infected cells had neuronal morphology. (E) Example of an infected GnRH neuron (yellow). (F-I) EAP1 protein content (red) was reduced in neurons infected with EAP1 sh1 (green). (F) The injection track, rich in eGFP-expressing neurons, shows fewer EAP1-positive cells (red) than neighboring areas. (G) Higher-magnification images illustrating the reduction in EAP1 immunoreactive material (red) in the nucleus of EAP1 sh1-infected cells (eGFP-positive, green) as compared with noninfected (eGFP-negative, red only) cells. (H) Same field as in G, but showing only EAP1 immunoreactivity (red) to illustrate the loss of EAP1 protein in EAP1 sh1-infected cells. (I) Fluorescence intensities in AUs based on measurements of 36 infected and 104 noninfected cells. ${ }^{* *} P<0.01$ versus noninfected cells. Scale bars: $20 \mu \mathrm{m}$ (D); $5 \mu \mathrm{m}$ (E); $50 \mu \mathrm{m}$ (F); $10 \mu \mathrm{m}(\mathbf{G}$ and $\mathbf{H})$. Numbers in parentheses represent number of wells per group, and error bars are SEM. Arrows in A-C point to sites of injection; arrows in $\mathbf{G}$ and $\mathbf{H}$ point to infected cells $(\mathbf{G})$ exhibiting a decrease in EAP1 immunoreactivety $(\mathbf{H})$.

level subordinate genes required for the productive interaction of neuronal and glial subsets involved in the neuroendocrine control of reproductive function. Until now, attempts to answer this question have been hampered by the scarcity of the information provided by our current reductionist approaches, but most of all because of the unavailability of appropriate technology.

Using a combination of DNA arrays and siRNA technology, we have now identified $E A P 1$, a gene of heretofore unknown function, as a novel component of the transcriptional machinery that regulates female reproductive function. EAP1 behaves like some other unique transcriptional regulators, such as enhancer of polycomb, that exhibit either transactivating or repressive activities, depending on the target promoter and the partners involved (33). The C3HC4 RING finger domain in EAP1 is located near the C terminus of the protein, in contrast to the RING finger-containing proteins involved in ubiquitination, which are localized to the $\mathrm{N}$ terminus (23). Because this location is also observed in RING finger domain-containing molecules endowed with corepressor activity
(34), it is likely that EAP1 affects gene transcription by interacting with specific partners. The finding that EAP1 transactivates the transcription of genes involved in facilitating gonadotropin output (e.g., $G n R H)$ while suppressing the expression of genes that inhibit $\mathrm{GnRH}$ neuronal function (such as the preproenkephalin gene) suggests that a function of EAP1 in the neuroendocrine brain is to coordinate the activity of neuronal networks controlling $\mathrm{GnRH}$ secretion. The initial results of ongoing studies (data not shown) examining the effects of EAP1 on the transcriptional activity of other important genes involved in the transsynaptic facilitatory/ inhibitory control of GnRH secretion, such as Kiss1 and GPR54, and those encoding proteins essential for glutamatergic and GABAergic neurotransmission (vesicular glutamate and GABA transporters) appear to confirm the validity of this concept. An additional, intriguing possibility deserving experimental scrutiny is an involvement of EAP1 in controlling the hypothalamic expression of genes that link energy homeostasis to reproductive development, such as those encoding the insulin, IGF-1, and/or leptin receptor. 
A

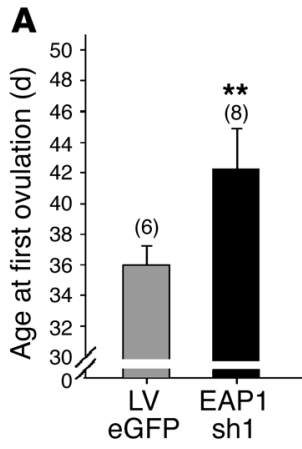

D

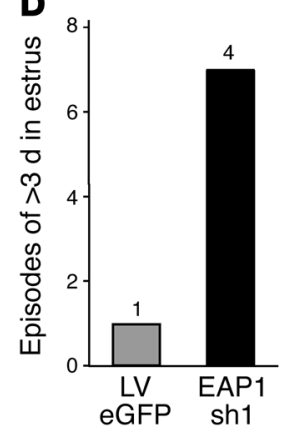

B

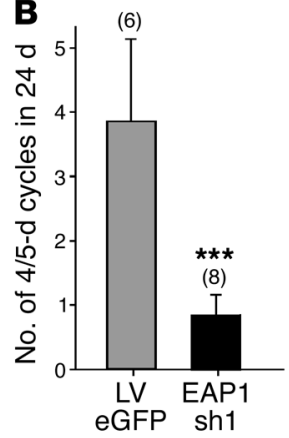

E

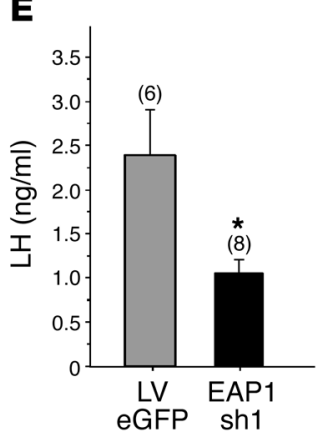

c
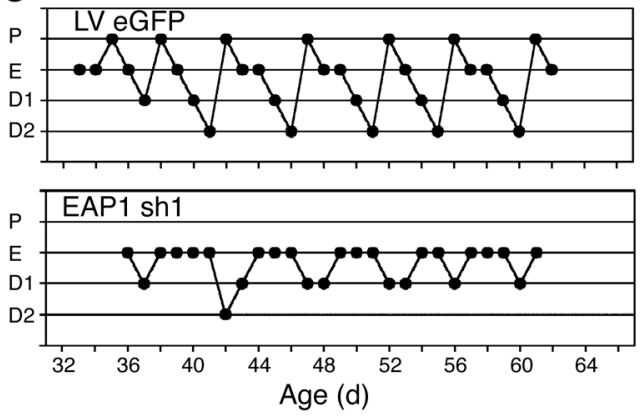

$\mathbf{F}$

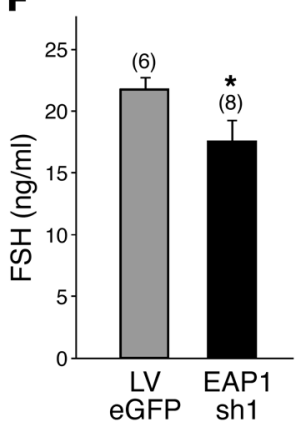

G

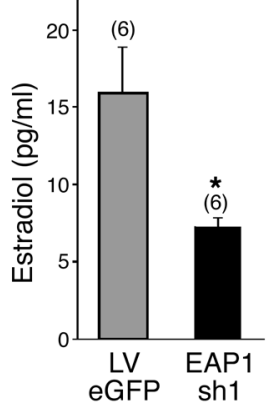

\section{Figure 6}

Site-restricted shRNA-mediated knockdown of the EAP1 gene targeted to the rat POA delays puberty, disrupts estrous cyclicity, and reduces plasma gonadotropin and estradiol levels. EAP1-knockdown animals exhibit: delayed puberty, assessed by the age of first ovulation (A); disruption of estrous cyclicity, determined in daily vaginal lavages ( $\mathbf{B}$ and $\mathbf{C}$, example of a disrupted cycle); episodes of persistent estrus (D); decreased serum $\mathrm{LH}(\mathrm{E}), \mathrm{FSH}(\mathbf{F})$, and estradiol levels (G). Numbers above bars represent number of animals per group, and error bars are SEM. ${ }^{*} P<0.05$, ${ }^{* \star} P<0.02$, and ${ }^{* * *} P<0.01$ versus LV eGFP-injected controls.
In earlier reports, we furnished evidence suggesting the involvement of 2 known genes in the transcriptional control of female puberty and adult female reproductive function. One of them is Oct2, a transcriptional regulator of the POU domain family of homeobox-containing genes (35). The Oct2 gene appears to be important for the trans-regulation of astroglial gene transcription, and TGF- $\alpha$, a key glial facilitator of GnRH secretion at puberty (36), has been shown to be one of its targets (37). Decreasing Oct2 expression via intraventricular administration of antisense oligonucleotides delayed rat female puberty (37), demonstrating the importance of this glial pathway in the control of female sexual development. The second candidate is thyroid transcription factor 1 (TTF1), another homeobox gene. TTF1 is required for diencephalic morphogenesis (38); after birth it remains expressed in selected neuronal and glial populations of the hypothalamus (39). Acting within diverse cellular subsets, TTF1 enhances the transcriptional activity of genes required for the facilitatory control of gonadotropin secretion (GnRH, erbB2, KiSS1), while repressing the transcription of a gene involved in the inhibition of $\mathrm{GnRH}$ neuronal function (preproenkephalin) $(39,40)$. Conditional deletion of the Ttf1 gene in differentiated neurons resulted in delayed female puberty, irregular estrous cyclicity, reduced reproductive capacity, and a shortened reproductive span, demonstrating the importance of this regulatory pathway for the normalcy of female reproductive function (40).

Although we do not know yet whether EAP1, TTF1, and Oct2 are hierarchically related, we know that, like that of TTF1 and Oct2, the initial pubertal increase in EAP1 expression is sex steroid independent (data not shown), suggesting that EAP1 represents a potentially important (and novel) component of the gonad-independent increase in "central drive" thought to initiate puberty in both rodents and primates $(1,4)$. Adding credence to the notion that the pubertal increase in hypothalamic EAP1 expression is caused by central events, rather than peripherally derived signals, is the finding of similar EAP1 mRNA levels in the hypothalamus of wild-type and leptin-deficient $o b / o b$ mice.

Although primates (1), but not rodents (2), exhibit a juvenile "hiatus" in gonadotropin secretion, the basic mechanisms underlying the onset of puberty are essentially the same. In both cases, puberty is initiated by a diurnal increase in pulsatile $\mathrm{GnRH}$ release, and the activity of GnRH neurons is controlled by the same regulatory neuronal and glial networks $(1,2,10)$. Our article further underscores this commonality.

The disruption of estrous cyclicity and reduction in plasma gonadotropin levels caused by the siRNA-mediated reduction of EAP1 expression in the POA of female rats suggest an alteration of $\mathrm{GnRH}$ release. Because these abnormalities were accompanied by stunted antral follicular development and formation of ovarian cysts, it is possible that a major consequence of the central loss of EAP1 is a disruption in pulsatile GnRH release. While this disruption may affect only circhoral changes in GnRH output, an alteration of the clockentrained, diurnal pattern of GnRH secretion - which is required for both the initiation of puberty (2) and the normalcy of estrous cyclicity (41) - remains a distinct possibility. EAP1-knockdown rats exhibit reduced serum FSH levels, which suggests that the accumulation of medium-size antral follicles observed in these animals is due, at least in part, to a diminished FSH support. The importance of adequate FSH levels for the continuous development of antral follicles is well documented (42). Although the concomitant presence of follicular and luteal cysts in the ovaries of EAP1-knockdown rats may be related to a lack of pulsatile $\mathrm{LH}$, it is also plausible that this abnormality is instead caused by factors (growth factors?) whose production may be affected (in a gonadotropin-independent manner) by the intrahypothalamic reduction of EAP1 expression. Further studies are required to distinguish between these possibilities.

Because EAP1 is located in the region of chromosome 14 affected in maternal uniparental disomy 14 , a syndrome with a complex phenotype that includes precocious puberty $(17,18)$, EAP1 might 


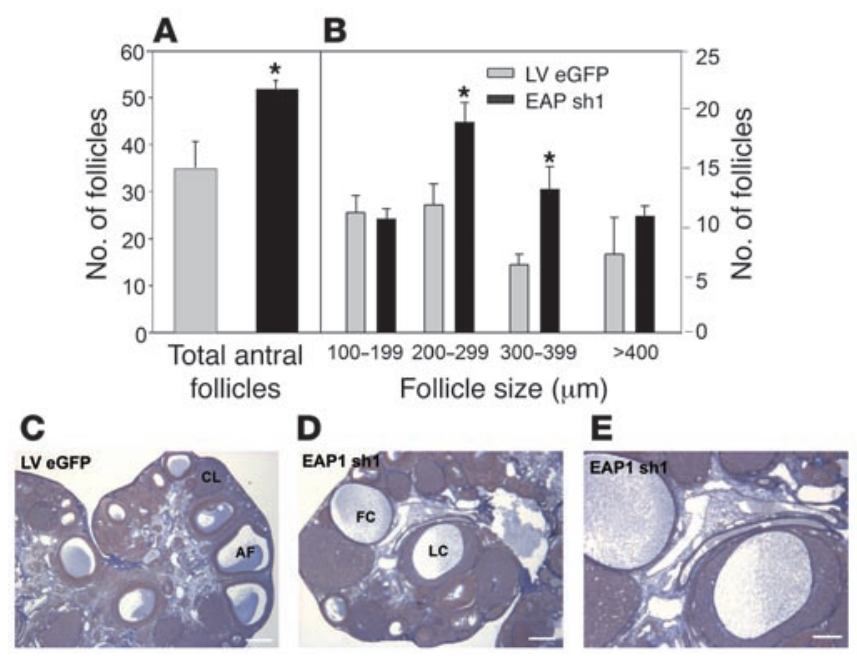

Figure 7

Site-restricted shRNA-mediated knockdown of the EAP1 gene targeted to the rat POA results in abnormal follicular development. (A) Normal ovarian follicle growth is disrupted as evidenced by an accumulation of antral follicles. (B) The accumulation is due to an increased number of medium-size antral follicles in the 200- to $400-\mu \mathrm{m}$ range. (C) Example of an ovary from an LV eGFP-injected control rat showing a normal complement of antral follicles (AF) and corpora lutea (CL). (D) The ovaries from EAP1 sh1-injected rats exhibited follicular and luteal cysts (FC and LC, respectively). (E) Higher-magnification view of $\mathbf{D}$. Each bar represents mean \pm SEM of 3 animals. ${ }^{*} P<0.05$ versus LV eGFP-injected controls.

represent one of the affected genes. Genetic studies in humans will be necessary to examine this tantalizing possibility.

The results obtained after reducing expression of the EAP1 gene in cells of the POA via lentivirus-mediated delivery of siRNAs do not permit us to conclude that EAP1 is a transcription factor essential for the occurrence of puberty and female reproductive cycles, but they unambiguously show that EAP1 is necessary for the normalcy of these processes. The availability of EAP1-null mice should allow researchers to determine whether EAP1 indeed has an essential role. The onset of female puberty and the central control of female reproductive cycles can be envisioned as processes governed by upper-echelon genes encoding transcription factors functionally connected to a multiplicity of downstream (subordinate) genes expressed in different neuronal and/or glial subsets controlling GnRH output (43). Studies in other cellular systems have shown that regulatory networks are controlled by a few highly connected "hubs" (15). Our results suggest that while EAP1, TTF1, and Oct2 can all be considered as upper-echelon genes, EAP1 may represent a major hub of the network.

\section{Methods}

Detailed descriptions of DNA microarrays, real-time PCR, semiquantitative PCR, in situ hybridization and immunohistochemistry, functional promoter assays and plasmid constructs, siRNA preparation and tests of siRNA biological activity, functional analysis of siRNA specificity, assessment of a lentivirus-induced interferon response, intrahypothalamic injections of lentiviral particles, imaging, and quantitation of EAP1 immunoreactivity are included as supplemental information.

Animals. The nonhuman primate brain tissues used in this study derived from juvenile ( 9 months to 1.8 years of age), early pubertal
(2-2.9 years of age), and mid-pubertal (3.1-4 years of age) female monkeys (Macaca mulatta) that had been euthanized and obtained through the Oregon National Primate Research Center (ONPRC) Necropsy Program. The animals were classified by stage of development according to the criteria reported by Watanabe and Terasawa (44). Plasma LH levels obtained from a different set of age-matched, contemporary animals ( $n=10$ /group) were $2.59 \pm 0.97 \mathrm{ng} / \mathrm{ml}$ (juvenile), $3.88 \pm 0.92 \mathrm{ng} / \mathrm{ml}$ (early puberty), and $6.48 \pm 1.64 \mathrm{ng} / \mathrm{ml}$ (mid-puberty), reflecting the pubertal maturation of the hypothalamic-pituitary axis.

Female Sprague-Dawley rats were purchased from B\&K Universal Ltd. They arrived at the laboratory when they were 21 days old and were housed under controlled conditions of temperature $\left(23-25^{\circ} \mathrm{C}\right.$ ) and light (14 hours of light, 10 hours of darkness; lights on from 5:00 am to 7:00 pm). Food (Purina laboratory chow; Ralston-Purina) and water were provided ad libitum. To determine the changes in EAP1 mRNA abundance that occur in the MBH and CTX at the time of puberty, female rats were euthanized at 3 different stages: juvenile ( 25 days of age), early puberty (30-35 days of age), and on the day of the first proestrus (32-37 days of age). Animals at this latter stage were considered as being in mid-puberty, as they had not yet ovulated. According to previously established criteria (2), 25-day-old animals are in the mid-juvenile phase of prepubertal development. At this time, the vagina is not yet patent and the uterine weight is $60 \mathrm{mg}$ or less, with no accumulation of intrauterine fluid. Older rats showing a closed vagina, accumulation of intrauterine fluid, and an uterine weight less that $180 \mathrm{mg}$ are considered to be in early puberty (early proestrous phase). Finally, rats still exhibiting a closed vagina but showing a uterus ballooned with fluid and a uterine weight of at least $200 \mathrm{mg}$ are considered to be in mid-puberty (late proestrus phase of puberty), i.e., when the first preovulatory surge of GnRH and gonadotropins takes place. The first ovulation occurs the following day. All animals were sacrificed between 4:00 and 5:00 pm.

The ob/ob mutant mice (Lepob/Lepob) and wild-type C57BL/6J controls used to evaluate the effect of leptin on hypothalamic EAP1 mRNA content were purchased from The Jackson Laboratory.

The brain regions collected from monkeys, rats, and mice were the $\mathrm{MBH}$ and samples from the CTX. The MBH was dissected by a rostral cut along the posterior border of the optic chiasm, a caudal cut immediately in front of the mammillary bodies, and 2 lateral cuts along the hypothalamic sulci. The thickness of the tissue fragment was about $4 \mathrm{~mm}$ (monkeys) and $2 \mathrm{~mm}$ (rats and mice). Upon dissection, the tissues were immediately frozen on dry ice and stored at $-85^{\circ} \mathrm{C}$ until RNA extraction.

To evaluate the effects of intrahypothalamic injections of lentiviruses encoding EAP1 shRNAs on female reproductive development and mature reproductive function, rats were injected (Supplemental Note 8) during the first half of the juvenile period (P23) and subsequently they were examined for vaginal opening, first ovulation, and estrous cyclicity using established criteria (2), as described below.

The use of nonhuman primates, rats, and mice was approved by the ONPRC Animal Care and Use Committee in accordance with the NIH guidelines for the use of animals in research.

Evaluation of sexual maturation and adult reproductive function. The animals were inspected every afternoon for vaginal opening, starting 7 days after the injection. Once vaginal opening occurred, vaginal lavages were performed daily to identify the occurrence of the first estrus, which in rodents is manifested by a predominance of cornified cells (2). Although ovulation normally occurs on the day of estrus (2), detection of cornified cells does not indicate that ovulation has occurred, unless vaginal cornification is followed by the appearance of a predominance of leukocytes (45). The presence of these cells defines the diestrous phase of the estrous cycle and indicates that a functional corpus luteum was formed after ovulation. For these reasons, the age at first ovulation was considered to have been 
reached only when the cornified cells were followed by at least 2 days of lavages containing mostly leukocytes (46).

Forty to 42 days after the intrahypothalamic injections, animals were anesthetized with tribromoethanol $(2.5 \mathrm{mg} / 100 \mathrm{~g}$ body wt), blood was collected via cardiac puncture for hormone evaluation, and the brains were perfusion fixed for immunohistochemical verification of the site of injection. Circulating LH and FSH levels and serum levels of ovarian steroids were measured by RIA, as described previously (47). The ovaries of rats that had been injected in the POA with EAP1 sh1 or LV eGFP control viral particles were removed, fixed in Kahle fixative, embedded in paraffin, serially sectioned at $6 \mu \mathrm{m}$, stained with Weigert iron hematoxylin, and counterstained with picric acid-methyl blue, as reported previously (48). Every tenth section was imaged on a Zeiss Axioplan, using a CoolSNAP camera (Roper Scientific). Follicles were counted using the manual count feature of MetaMorph (Universal Imaging Co.). Only follicles in which the nucleus of the oocyte was visible were counted, and the total number of follicles per ovary was determined as reported previously (48). All counts were performed without previous knowledge of the animal's treatment.

$D N A$ microarrays, real-time PCR, and promoter assays. The changes in gene expression taking place at the time of puberty in the monkey hypothalamus were assessed using human cDNA microarrays (Supplemental Note 1), and the results were validated using a previously described real-time PCR protocol (49) (Supplemental Note 2). Assessment of the trans-regulatory activity of EAP1 (Supplemental Note 4) was performed as described previously (39).

Cloning of rat, monkey, and human EAP1. Partial EAP1 cDNAs or cDNAs containing the entire EAP1 coding region from each of these 3 species were cloned into plasmid vectors after PCR amplification of reverse-transcribed mRNA (Supplemental Notes 2 and 4).

Design and construction of siRNAs. To generate siRNAs against rat EAP1 mRNA (Supplemental Note 5), we first cloned EAP1 mRNA from rat hippocampal HiB5 cells (Supplemental Note 6) and sequenced its entire coding region (GenBank accession number AY879229). Three pre-designed siRNAs targeting nt 1,309-1,327 (siR1), 1,471-1,489 (siR2), and 1,6181,636 (siR3) of EAP1 mRNA were tested for activity as described in Supplemental Note 5 . The 2 most potent siRNAs (siR1 and siR3) were subjected to functional analysis to verify their target specificity employing EAP1 mRNAs carrying point mutations of the region targeted by each siRNA (Supplemental Note 6). The sequence of siR1 was then used to generate an EAP1 shRNA construct.

Preparation of EAP1 shRNAs and production of viruses. A 53-mer oligodeoxynucleotide containing the 19-nt sense and antisense EAP1 siRNA-encoding strands separated by the 9-nt loop shown in Figure 4B was cloned into the Apa I-EcoR I sites of the multiple cloning site of a cassette (derived from the vector pSilencer 1.0-U6; Ambion) in which transcription of siRNAs is directed by the U6 RNA polymerase promoter (50). This cassette, inserted into the $3^{\prime}$ LTR of a lentiviral construct (27), is able to deliver encoded siRNAs into the brain (51).

To produce virus particles, we used the calcium phosphate method (52) to cotransfect 293T cells with 4 plasmids; the lentiviral-siRNA vector, pLP1, pLP2, and pLPv (Invitrogen) $(27,53)$. Plasmid pLP1 expresses gag and pol; PLP2 expresses Rev; and PLPv expresses the VSVG envelope protein. The viral concentration was increased by ultracentrifugation (54), and the titer of the viral stock was determined by infection of naive $293 \mathrm{~T}$ cells. Following infection with serial dilutions of the viral stock, the percentage of GFPpositive (fluorescent) cells was determined by flow cytometry in the Core facility at the Vaccine and Gene Therapy Institute, ONPRC (Supplemental Figure 2). The titer was expressed as transducing units per milliliter $(\mathrm{TU} / \mathrm{ml})$. To test the effectiveness of the viral particles carrying EAP1 shRNA-encoding cassettes, we used HiB5 cells. They were seeded in a 6-well plate at a density of 400,000 cells/well in antibiotic-free DMEM medium. The following day they were infected with control (LV eGFP) viruses, EAP1 sh1, or EAP sh3 (at $0.6 \times 10^{9}$ to $3.5 \times 10^{9} \mathrm{TU} / \mathrm{ml}$ ) in a $1-\mathrm{ml}$ volume containing Polybrene $(16 \mu \mathrm{g} / \mathrm{ml})$. Total RNA was extracted 72 hours after the infection, and the content of EAP1 mRNA was measured by semiquantitative PCR as described in Supplemental Note 2.

In situ bybridization and immunohistochemistry. The brains of monkeys and rats were subjected to hybridization and/or immunostaining as described in Supplemental Note 3.

Imaging. After completion of the immunofluorescence reactions (Supplemental Note 3), fluorescent images were acquired and analyzed as described in Supplemental Note 9.

Statistics. Differences between 2 groups of animals or independent observations were analyzed using 2-tailed Student's $t$ test. When several groups were compared, the differences were analyzed by 1-way ANOVA followed by the Student-Neuman-Keuls multiple comparison test for unequal replications.

\section{Acknowledgments}

We thank Anda Cornea (ONPRC Imaging and Morphology Core) for imaging and imaging analysis and W. Les Dees (Department of Veterinary Anatomy and Public Health, Texas A\&M University, College Station, Texas, USA) for performing the LH and FSH radioimmunoassays. We also thank Maria Costa, Leela Goodspeed, Brigitte Andresen, and Gisela Hohmann for expert technical assistance. This work was supported by grants from the NIH, the National Institute of Child Health and Human Development/NIH (to S.R. Ojeda), the European Society for Paediatric Endocrinology (to H. Jung), the German Research Foundation (to S. Heger), and the European Commission (PIONEER to S. Heger).

Received for publication February 8, 2007, and accepted in revised form April 24, 2007.

Address correspondence to: Sergio R. Ojeda, Division of Neuroscience, Oregon National Primate Research Center, Oregon Health \& Science University, 505 NW 185th Avenue, Beaverton, Oregon, USA. Phone: (503) 690-5302; Fax: (503) 690-5384; E-mail: ojedas@ohsu.edu.

Sabine Heger's present address is: Department of Pediatric Endocrinology, Children's Hospital auf der Bult, Hannover, Germany.

Claudio Mastronardi's present address is: Department of Psychiatry and Behavioral Sciences, University of Miami School of Medicine, Miami, Florida, USA.

Ricardo Cabrera's present address is: Laboratorio de Investigaciones Neuroquimicas y Endocrinas, Universidad Nacional de Cuyo, Mendoza, Argentina.

Christian L. Roth's present address is: Department of Pediatrics, Seattle Children's Hospital Research Institute, Seattle, Washington, USA.

Heike Jung's present address is: Eli Lilly \& Co., Bad Homburg, Germany.

Sabine Heger and Claudio Mastronardi contributed equally to this work. 
1. Plant, T.M., and Witchel, S.F. 2006. Puberty in nonhuman primates and humans. In The physiology of reproduction. 3rd edition. J.D. Neill, editor. Academic Press/Elsevier. San Diego, California, USA. 2177-2230.

2. Ojeda, S.R., and Skinner, M.K. 2006. Puberty in the rat. In The physiology of reproduction. 3rd edition. J.D. Neill, editor. Academic Press/Elsevier. San Diego, California, USA. 2061-2126.

3. Kordon, C., Drouva, S.V., Martínez de la Escalera, G., and Weiner, R.I. 1994. Role of classic and peptide neuromediators in the neuroendocrine regulation of luteinizing hormone and prolactin. In The physiology of reproduction. 2 nd edition. Volume 1. E. Knobil and J.D. Neill, editors. Raven Press. New York, New York, USA. 1621-1681.

4. Ojeda, S.R., and Terasawa, E. 2002. Neuroendocrine regulation of puberty. In Hormones, brain and behavior. Volume 4. D. Pfaff et al., editors. Elsevier. New York, New York, USA. 589-659.

5. Ojeda, S.R., et al. 2003. Glia-to-neuron signaling and the neuroendocrine control of female puberty. Ann. Med 35:244-255.

6. Terasawa, E., and Fernandez, D.L. 2001. Neurobiological mechanisms of the onset of puberty in primates. Endocr. Rev. 22:111-151.

7. Dungan, H.M., Clifton, D.K., and Steiner, R.A. 2006. Minireview: kisspeptin neurons as central processors in the regulation of gonadotropin-releasing hormone secretion. Endocrinology. 147:1154-1158.

8. DeFazio, R.A., Heger, S., Ojeda, S.R., and Moenter, S.M. 2002. Activation of A-type $\gamma$-aminobutyric acid receptors excites gonadotropin-releasing hormone neurons. Mol. Endocrinol. 16:2872-2891.

9. Krewson, T.D., et al. 2004. Chromosomes 6 and 13 harbor genes that regulate pubertal timing in mouse chromosome substitution strains. Endocrinology. 145:4447-4451.

10. Seminara, S.B., and Crowley, W.F., Jr. 2001. Perspective: the importance of genetic defects in humans in elucidating the complexities of the hypothalamic-pituitary-gonadal axis. Endocrinology. 142:2173-2177.

11. Palmert, M.R., and Hirschhorn, J.N. 2003. Genetic approaches to stature, pubertal timing, and other complex traits. Mol. Genet. Metab. 80:1-10.

12. de Vries, L., Kauschansky, A., Shohat, M., and Phillip, M. 2004. Familial central precocious puberty suggests autosomal dominant inheritance. J. Clin. Endocrinol. Metab. 89:1794-1800.

13. Ojeda, S.R. 1991. The mystery of mammalian puberty: how much more do we know? Perspect Biol. Med. 34:365-383

14. Davidson, E.H., et al. 2002. A genomic regulatory network for development. Science. 295:1669-1678.

15. Basso, K., et al. 2005. Reverse engineering of regulatory networks in human B cells. Nat. Genet. 37:382-390.

16. Rampazzo, A., et al. 2000. Characterization of C14orf4, a novel intronless human gene containing a polyglutamine repeat, mapped to the ARVD1 critical region. Biochem. Biophys. Res. Commun. 278:766-774.

17. Sutton, V.R., and Shaffer, L.G. 2000. Search for imprinted regions on chromosome 14: comparison of maternal and paternal UPD cases with cases of chromosome 14 deletion. Am. J. Med. Genet. 93:381-387.

18. Martin, R.A., Sabol, D.W., and Rogan, P.K. 1999. Maternal uniparental disomy of chromosome 14 confined to an interstitial segment (14q23- 14q24.2). J. Med. Genet. 36:633-636.

19. Bhanot, R., and Wilkinson, M. 1983. Opiatergic control of gonadotropin secretion during puberty in the rat. Endocrinology. 113:596-602.

20. Ebling, F.J., Schwartz, M.L., and Foster, D.L. 1989. Endogenous opioid regulation of pulsatile luteinizing hormone secretion during sexual maturation in the female sheep. Endocrinology. 125:369-383.

21. Morris-Desbois, C., Bochard, V., Reynaud, C., and Jalinot, J. 1999. Interaction between the Ret finger protein and the int- 6 gene product and co-localisation into nuclear bodies. J. Cell Sci. 112:3331-3342.

22. Burkhard, P., Stetefeld, J., and Strelkov, S.V. 2001. Coiled coils: a highly versatile protein folding motif. Trends Cell Biol. 11:82-88.

23. Sauring, A.J., Borden, K.L.B., Boddy, M.N., and Freemont, P.S. 1996. Does this have a familiar RING? Trends Biochem. Sci. 21:208-214.

24. Freemont, P.S. 2000. RING for destruction? Curr. Biol. 10:R84-R87.

25. Waterman, H., Levkowitz, G., Alroy, I., and Yarden, Y. 1999. The RING finger of c-Cbl mediates desensitization of the epidermal growth factor receptor. J. Biol. Chem. 274:22151-22154.

26. Bridge, A.J., Pebernard, S., Ducraux, A., Nicoulaz, A.-L., and Iggo, R. 2003. Induction of an interferon response by RNAi vectors in mammalian cells. Nat. Genet. 34:263-264.

27. Tiscornia, G., Singer, O., Ilawa, M., and Verma, I.M. 2003. A general method for gene knockdown in mice by using lentiviral vectors expressing small interfering RNA. Proc. Natl. Acad. Sci. U. S. A. 100:1844-1848.

28. Sledz, C.A., Holko, M., deVeer, M.J., Silverman, R.H., and Williams, B.R.G. 2003. Activation of the interferon system by short-interfering RNAs. Nat. Cell Biol. 5:834-839.

29. Herbison, A.E. 2006. Physiology of the gonadotropin-releasing hormone neuronal network. In The physiology of reproduction. 3rd edition. J.D. Neill, editor. Academic Press/Elsevier. San Diego, California USA. $1415-1482$

30. Simerly, R.B. 2002. Wired for reproduction: organization and development of sexually dimorphic circuits in the mammalian forebrain. Annu. Rev. Neurosci. 25:507-536

31. Farooqi, I.S., et al. 1999. Effects of recombinant leptin therapy in a child with congenital leptin deficiency. N. Engl. J. Med. 341:879-884.

32. Ahima, R.S., Saper, C.B., Flier, J.S., and Elmquist, J.K. 2000. Leptin regulation of neuroendocrine systems. Front. Neuroendocrinol. 21:263-307.

33. Shimono, Y., Murakami, H., Hasegawa, Y., and Takahashi, M. 2000. RET finger protein is a transcriptional repressor and interacts with enhancer of polycomb that has dual transcriptional functions. J. Biol. Chem. 275:39411-39419.

34. Childs, K.S., and Goodbourn, S. 2003. Identification of novel co-repressor molecules for interferon regulatory factor-2. Nucleic Acids Res. 31:3016-3026

35. Treacy, M.N., and Rosenfeld, M.G. 1992. Expression of a family of POU-domain protein regulatory genes during development of the central nervous system. Annu. Rev. Neurosci. 15:139-165.

36. Ma, Y.J., Junier, M.-P., Costa, M.E., and Ojeda, S.R 1992. Transforming growth factor alpha (TGF $\alpha)$ gene expression in the hypothalamus is developmentally regulated and linked to sexual maturation. Neuron. 9:657-670

37. Ojeda, S.R., et al. 1999. The Oct-2 POU-domain gene in the neuroendocrine brain: a transcriptional regulator of mammalian puberty. Endocrinology. 140:3774-3789

38. Kimura, S., et al. 1996. The T/ebp null mouse: thyroid-specific enhancer-binding protein is essential for the organogenesis of the thyroid, lung, ventral forebrain, and pituitary. Genes Dev. 10:60-69.

39. Lee, B.J., et al. 2001. TTF-1, a homeodomain gene required for diencephalic morphogenesis, is postnatally expressed in the neuroendocrine brain in a developmentally regulated and cell-specific fashion. Mol. Cell. Neurosci. 17:107-126.

40. Mastronardi, C., et al. 2006. Deletion of the Ttf1 gene in differentiated neurons disrupts female reproduction without impairing basal ganglia function. J. Neurosci. 26:13167-13179.

41. Freeman, M.E. 2006. Neuroendocrine control of the ovarian cycle of the rat. In The physiology of reproduction. 3rd edition. J.D. Neill, editor. Academic Press/Elsevier. San Diego, California, USA. 2327-2388

42. Rajkovic, A., Pangas, S.A., and Matzuk, M.M. 2006. Follicular development: mouse, sheep, and human models. In The physiology of reproduction. 3rd edition. J.D. Neill, editor. Academic Press/Elsevier. San Diego, California, USA. 383-423.

43. Ojeda, S.R., et al. 2006. Minireview: the neuroendocrine regulation of puberty: is the time ripe for a systems biology approach? Endocrinology. 147:1166-1174.

44. Watanabe, G., and Terasawa, E. 1989. In vivo release of luteinizing hormone releasing hormone increases with puberty in the female rhesus monkey. Endocrinology. 125:92-99.

45. Nelson, J.F., Karelus, K., Felicio, L.S., and Johnson, T.E. 1990. Genetic influences on the timing of puberty in mice. Biol. Reprod. 42:649-655.

46. Prevot, V., et al. 2003. Normal female sexual development requires neuregulin-erbB receptor signaling in hypothalamic astrocytes. J. Neurosci. 23:230-239.

47. Dissen, G.A., et al. 2000. Intraovarian excess of nerve growth factor increases androgen secretion and disrupts estrous cyclicity in the rat. Endocrinology. 141:1073-1082.

48. Dissen, G.A., Romero, C., Hirshfield, A.N., and Ojeda, S.R. 2001. Nerve growth factor is required for early follicular development in the mammalian ovary. Endocrinology. 142:2078-2086.

49. Shahab, M., et al. 2005. Increased hypothalamic GPR54 signaling: a potential mechanism for initiation of puberty in primates. Proc. Natl. Acad. Sci. U. S. A. 102:2129-2134.

50. Miyagishi, M., and Taira, K. 2002. U6 promoterdriven siRNAs with four uridine $3^{\prime}$ overhangs efficiently suppress targeted gene expression in mammalian cells. Nat. Biotechnol. 19:497-500.

51. Singer, O., et al. 2005. Targeting BACE1 with siRNAs ameliorates Alzheimer disease neuropathology in a transgenic model. Nat. Neurosci. 8:1343-1349.

52. Chen, C.A., and Okayama, H. 1988. Calcium phosphate-mediated gene transfer: a highly efficient transfection system for stably transforming cells with plasmid DNA. Biotechniques. 6:632-638.

53. Naldini, L., et al. 1996. In vivo gene delivery and stable transduction of nondividing cells by a lentiviral vector. Science. 272:263-267.

54. Kootstra, N.A., et al. 2003. Abrogation of postentry restriction of HIV-1-based lentiviral vector transduction in simian cells. Proc. Natl. Acad. Sci.U.S. A. 100:1298-1303. 